\title{
Formação de professores para o uso de tecnologias digitais: Um relato de experiência no Colégio Estadual Professora Luzia Carvalho Silva
}

\author{
Teacher education for the use of digital technologies: An experience report at Colegio Estadual \\ Professora Luzia Carvalho Silva \\ Formación docente para el uso de tecnologías digitales: Un relato de experiencia en el Colegio \\ Estadual Profesora Luzia Carvalho Silva
}

Recebido: 22/03/2021 | Revisado: 28/03/2021 | Aceito: 02/04/2021 | Publicado: 12/04/2021

\author{
José Batista de Souza \\ ORCID: https://orcid.org/0000-0001-9722-8818 \\ Faculdade do Nordeste da Bahia, Brasil \\ E-mail: batistinhadesouza@gmail.com \\ Tainah dos Santos Carvalho \\ ORCID: https://orcid.org/0000-0002-2516-0380 \\ Faculdade do Nordeste da Bahia, Brasil \\ E-mail: santostainah70@gmail.com
}

\begin{abstract}
Resumo
A formação de professores para o uso de Tecnologias Digitais da Informação e Comunicação (TDIC) nos processos de ensino e de aprendizagem, há muito tempo, tem sido uma temática alvo do interesse dos pesquisadores da educação, pois há uma necessidade constante de entender como essa relação entre formação docente e tecnologias digitais pode contribuir para um ensino de qualidade. No atual contexto, marcado pela pandemia de Covid-19, este tema ganha ainda mais notoriedade, principalmente porque, diferentemente de tempos não pandêmicos, hoje, as tecnologias digitais se apresentam como o principal meio de levar educação aos estudantes. Assim, este trabalho tem como objetivo apresentar uma experiência exitosa acerca do uso de tecnologias digitais por professores durante a Jornada Pedagógica Paulo Freire 2020/2021, no Colégio Estadual Professora Luzia Carvalho Silva, na Bahia. Como metodologia, adotamos a pesquisa bibliográfica, e o relato de experiência, por meio do qual descrevemos e analisamos a socialização de diferentes ferramentas digitais por professores durante o evento de abertura do ano letivo. A partir dessa experiência, os resultados apontaram que, apesar das dificuldades dos professores em lecionar a partir de tecnologias digitais, eles se mostraram abertos a aprender e a usar alguns dos recursos apresentados em suas aulas remotas. Como conclusão, ficou nítido que, no espaço escolar, a troca de experiência entre os docentes contribui significativamente para a melhoria dos processos de ensino e de aprendizagem e para uma maior aproximação entre os professores.
\end{abstract}

Palavras-chave: Ensino remoto; Formação docente; Prática docente; Tecnologias digitais.

\begin{abstract}
Teacher training for the use of Digital Technologies of Information and Communication (DTIC) in teaching and learning processes has long been a topic of interest to education researchers, as there is a constant need to understand how this relationship between teacher training and digital technologies can contribute to teaching Of Quality. In the current context, marked by the Covid-19 pandemic, this theme gains even more notoriety, mainly because, unlike non-pandemic times, today, digital technologies are presented as the main means of bringing education to students. Thus, this work aims to present a successful experience on the use of digital technologies by teachers during the Paulo Freire 2020/2021 Pedagogical Journey, at Colegio Estadual Professora Luzia Carvalho Silva in Bahia. As a methodology, we adopted bibliographic research, and the experience report, through which we describe and analyze the socialization of different digital tools by teachers during the opening event of the school year. Based on this experience, the results showed that, despite the teachers' difficulties in teaching using digital technologies, they were open to learning and using some of the resources presented in their remote classes. As a conclusion, it was clear that, in the school space, the exchange of experience among teachers contributes significantly to the improvement of the teaching and learning processes and to a closer relationship between teachers.
\end{abstract}

Keywords: Remote education; Teacher training; Teaching practice; Digital technologies. 


\begin{abstract}
Resumen
La formación del profesorado para el uso de las Tecnologías Digitales de la información y la comunicación en los procesos de ensenãnza y aprendizaje a ha sido durante mucho tiempo un tema de interés para los investigadores en educación, ya que existe una necesidad constante de comprender cómo esta relación entre la formación del profesorado y las tecnologías digitales puede contribuir a la enseñanza de la Calidad. En el contexto actual, marcado por la pandemia Covid-19, este tema gana aún más notoriedad, principalmente porque, a diferencia de épocas no pandémicas, hoy las tecnologías digitales se presentan como el principal medio para llevar la educación a los estudiantes. Así, este trabajo tiene como objetivo presentar una experiencia exitosa sobre el uso de tecnologías digitales por parte de los docentes durante el Viaje Pedagógico Paulo Freire 2020/2021, en el Colegio Estadual Professora Luzia Carvalho Silva, en la Bahía. Como metodología se adoptó la investigación bibliográfica, y el relato de experiencia, mediante el cual describimos y analizamos la socialización de diferentes herramientas digitales por parte de los docentes durante el acto inaugural del curso escolar. A partir de esta experiencia, los resultados mostraron que, a pesar de las dificultades de los docentes para enseñar utilizando tecnologías digitales, estaban abiertos a aprender y utilizar algunos de los recursos presentados en sus clases remotas. Como conclusión, quedó claro que, en el espacio escolar, el intercambio de experiencias entre docentes contribuye significativamente a la mejora del procesos de enseñanza y aprendizaje y a una relación más estrecha entre los docentes.
\end{abstract}

Palabras clave: Educación a distancia; Formación de profesores; Práctica docente; Tecnologías digitales.

\title{
1. Introdução
}

A formação docente para o uso de tecnologias digitais no ensino, há muito tempo, já faz parte das preocupações educacionais de alguns autores (Carvalho; Ivanoff, 2010; Braga, 2013; Almeida et al, 2015; Ostrovski; Raitz, 2016; Mendes; Champaoski, 2017; Hess; Assis; Viana, 2019, Oliveira; Amaral, 2020, entre outros), porém, neste tempo de pandemia de Covid-19, tais preocupações têm aumentado exponencialmente, devido à necessidade de efetivação de um ensino de qualidade por parte dos professores (mesmo diante das adversidades), tendo em vista que o ensino remoto, na maior parte dos casos, está sendo realizado por meio dessas tecnologias, devido ao distanciamento social que este momento pandêmico exige ${ }^{1}$.

Assim, estar familiarizado com diferentes ferramentas digitais, a partir de diferentes cursos de formação continuada em serviço, e de algumas trocas de experiências entre pares, é algo que se espera dos professores, uma vez que essa familiarização vai possibilitá-los a adquirir segurança e o traquejo necessários para conduzir os processos de ensino e de aprendizagem de forma adequada.

De acordo com Vicente e Almeida (2017, p. 03), "um dos pontos significativos ao se debater a utilização das tecnologias na formação de professores é a autonomia docente”. Dessa forma, quanto mais o professor dominar diferentes tecnologias digitais e conseguir contextualizá-las para o ensino, mais diversificado será o seu trabalho, algo que, consequentemente, poderá implicar positivamente na aprendizagem dos alunos.

Atualmente, estados e municípios têm empreendido esforços para preparar seus professores para o uso de tecnologias digitais no ensino, a exemplo do estado da Bahia que, recentemente, por meio do Instituto Anísio Teixeira (IAT), ofertou aos professores da rede estadual os cursos: (1) Curso de Ferramentas Digitais na Educação e (2) Curso de Produção de Aulas Online $e^{2}$

Assim, percebe-se que, apesar das dificuldades que geralmente os professores enfrentam para se familiarizarem com as tecnologias digitais no ensino, está havendo uma preocupação por parte do estado com essa formação, pela compreensão de que não se pode exigir dos professores mudança de postura de ensino sem o mínimo de formação. Mas a necessidade de domínio e uso de diferentes ferramentas tecnológicas é tão urgente que muitos professores não têm esperado apenas os cursos ofertados pelo governo, buscando outras formas de se capacitar, compreendendo que as necessidades do momento não podem esperar iniciativas a médio e longo prazos.

\footnotetext{
${ }^{1}$ Disponível em: https://coronavirus.saude.mg.gov.br/blog/108-distanciamento-social. Acesso em 01 de abril de 2021.

2 Disponível em: http://educadores.educacao.ba.gov.br/noticias/secretaria-da-educacao-abre-inscricoes-para-formacao-continuada-emtecnologias-na-educacao. Acesso em 31 de março de 2021.
} 
Tem sido comum, durante este período, os professores irem em busca, por conta própria, de formação (pelo menos básica) para o uso de tecnologias digitais, principalmente por cursos gratuitos, tutoriais disponíveis na internet e ajuda de seus pares, e isso já vinha ocorrendo antes da pandemia. Muitos professores já vinham se preocupando com essa formação, prova disso é que, segundo a última pesquisa divulgada pela TIC Educação (2019), por meio do site Cetic.br ${ }^{3}$, os professores têm buscado se atualizar no uso de tecnologias digitais de diferentes formas. Nesta pesquisa, os dados demonstraram que os professores geralmente aprendem sozinhos (93 participantes); com outras pessoas (84 participantes); com outros professores, informalmente (82 participantes); com vídeos ou tutoriais online (81 participantes); com formadores de outras instituições externas à escola (43 participantes); formadores da Secretaria de Educação (26 participantes), entre outras formas.

Nessa perspectiva, a preocupação dos professores com a própria formação em serviço é importante porque "[...] à medida que cada educador se volta para um processo de construção, desconstrução e reconstrução de sua prática, a tendência é que ocorra uma mudança na sua prática pedagógica, qualificando o trabalho docente" (Modelski; Azeredo; Giraffa, 2018, p. 119).

Com a pandemia, a suspensão das aulas presenciais e a necessidade de trabalhar remotamente, em muitos momentos fazendo uso da educação online ${ }^{4}$, os professores sentiram a necessidade de ampliar ainda mais seu repertório com as tecnologias digitais para o ensino, para poder chegar até seus alunos e conseguir efetuar um bom trabalho, mesmo remotamente.

Com base nesse cenário, questiona-se: como os professores têm encarado a necessidade de levar adiante o ensino remoto a partir do uso de tecnologias digitais?

À luz desse contexto, o presente trabalho tem, como objetivo, o de apresentar uma experiência exitosa acerca do uso de tecnologias digitais por professores do ensino médio, tendo como lócus o Colégio Estadual Professora Luzia Carvalho Silva, situado no município de Antas - Bahia, no qual professores, a partir da troca de experiências com o uso de tecnologias digitais têm se ajudado, visando oferecer aos alunos da instituição um ensino remoto de qualidade, principalmente no que tange à diversificação das ferramentas digitais.

\section{Metodologia}

O universo desta pesquisa foi o Colégio Estadual Professora Luzia Carvalho Silva - CEPLCS, situado no município de Antas - Bahia, e os participantes foram 08 professores de um total de 11, que aceitaram participar espontaneamente da pesquisa e oferecer imagens de suas produções relativas ao uso de tecnologias digitais durante o ensino remoto de 2020, para objeto de análise por parte dos pesquisadores ${ }^{5}$. São professores do ensino médio, com formação que varia entre a graduação e o mestrado. Quanto ao tempo de realização da pesquisa, a mesma ocorreu entre os dias 8 e 12 de março de 2021, durante a Jornada Pedagógica Paulo Freire, realizada pela Secretaria de Educação do Estado da Bahia.

Optamos pela pesquisa de abordagem qualitativa para a condução do presente trabalho por ter, segundo Ludke e André (1986, p. 11) "o ambiente natural como sua fonte direta de dados e o pesquisador como seu principal instrumento. [...] Supõe o contato [...] do pesquisador com o ambiente e a situação que está sendo investigada".

\footnotetext{
${ }^{3}$ Disponível em: https://www.cetic.br/media/analises/tic_educacao_2019_coletiva_imprensa.pdf. Acesso em 14 de março de 2021.

${ }^{4}$ Educação realizada de forma síncrona, através de tecnologias digitais, a exemplo da webconferência na plataforma Google Meet e da plataforma Zoom.

${ }^{5}$ Dos 11 professores, 2 optaram por apenas assistir à apresentação dos colegas para aprender sobre as ferramentas, e 1 não pôde participar da jornada nesse dia específico.
} 
A pesquisa bibliográfica foi adotada no trabalho porque "caracteriza-se pelo exame ou consulta de livros ou documentação escrita [...] para refazer caminhos já percorridos e [...] repensar o mundo [...] é realizada com o intuito de ampliar nossos conhecimentos teóricos acerca de algum assunto". (Rampazzo; Corrêa, 2008, p. 65). Além disso, ela contribui significativamente para a análise dos dados encontrados.

Também fizemos uso do relato de experiência narrativa, descrevendo passo a passo como se deu a experiência, e analisando-a à luz de um aporte teórico pertinente à temática em questão. A escolha do relato de experiência se deu porque, segundo Daltro e Faria (2019, p. 224), é “[...] mais uma possibilidade de criação de narrativa científica, especialmente no campo das pesquisas capazes de englobar processos e produções subjetivas [...].

Por questões éticas, os nomes dos professores participantes da pesquisa não serão mencionados durante o relato de experiência, sendo representados na ordem por P1, P2, P3, P4, P5, P6, P7 e P8.

\subsection{Socialização de ferramentas digitais pelos professores do CEPLCS}

Durante a Jornada Pedagógica Paulo Freire 2020/2021 $1^{6}$, realizada por todo o estado da Bahia remotamente, ficou acordado que o ano letivo contínuo ocorreria de três maneiras diferentes, levando-se em conta a incerteza gerada pela pandemia de Covid-19 e a necessidade de prosseguir com o processo educativo de forma sistematizada.

Conforme a organização estabelecida pela Secretaria de Educação do Estado da Bahia, no primeiro momento (esses primeiros meses do ano de 2021), o ensino será totalmente remoto, ocorrendo de segunda a sábado por meio de diferentes ferramentas digitais a critério dos professores, respeitando uma parte da carga horária para momentos síncronos e outra para momentos assíncronos. No segundo momento (quando o pico da pandemia diminuir significativamente), o ensino ocorrerá de forma híbrida, sendo 50\% do tempo de estudos presencial e 50\% remoto, com um revezamento entre os estudantes para a parte presencial. No terceiro momento (em uma possibilidade de controle da pandemia), o ensino voltará ao seu formato normal, ocorrendo de forma totalmente presencial.

A Jornada Pedagógica do Estado da Bahia ${ }^{7}$ acontece todo ano e, com um tema diferente. Esse ano, por exemplo, a temática escolhida foi Jornada Pedagógica Paulo Freire, em homenagem ao centenário desse ícone da educação brasileira. A referida jornada abarca todas as escolas da rede estadual, tendo como público-alvo gestores escolares, coordenadores pedagógicos, professores e alunos. É comandada pelo Secretário de Educação do Estado, juntamente com sua equipe, e tem a participação do governador em sua abertura. Especialmente este ano, devido ao contexto atípico, os alunos tiveram uma participação maior, inclusive muitos foram selecionados para participar dando depoimentos, representando diferentes escolas da rede e reforçando a necessidade de adesão dos estudantes ao ensino remoto. Além disso, para abrilhantar o evento, o Secretário de Educação convidou Fátima Freire, filha de Paulo Freire, que encantou a todos com sua participação.

A Jornada Pedagógica Paulo Freire durou 5 dias (8 a 12 de março), como se pode ver na programação disponibilizada no site do evento. Todas as manhãs desses 5 dias, os professores do estado tiveram a incumbência de assistir às webinars/lives da Secretaria de Educação do Estado no Youtube, no canal do evento, com duração média de 1 e meia a 2 horas. Nesses mesmos dias, no turno vespertino, cada escola, isoladamente, dava continuidade à jornada pelo Google Meet com sua equipe, seguindo às orientações do roteiro disponibilizado pela SEC e discutindo pontos específicos da sua realidade. Durante esse período, cada escola tinha liberdade para conduzir a jornada e acrescentar pontos que achassem relevantes, desde que contemplassem o roteiro prévio da SEC.

\footnotetext{
${ }^{6}$ As informações que tecem essa experiência partem do diário de campo de um dos pesquisadores, que também é professor da instituição, registradas durante a Jornada Pedagógica Paulo Freire 2020/2021.

${ }^{7}$ Disponível em http://jornadapedagogica.educacao.ba.gov.br/sugestao-de-programacao/. Acesso em 31 de março de 2021.
} 
Em um dos dias da jornada, no período vespertino, durante uma ampla discussão entre equipe diretiva, pedagógica e docente do Colégio Estadual Professora Luzia Carvalho Silva, acerca da necessidade de maior engajamento dos professores com as tecnologias digitais para levar adiante o ensino remoto, foi lançado aos professores o desafio de cada um se preparar para apresentar aos colegas (no dia seguinte), uma ferramenta digital com a qual tivesse um certo traquejo e da qual tivesse feito uso frequente no ensino remoto em 2020.

Apesar de um certo receio inicial, já que o desafio não era algo que estava no planejamento da jornada, os professores não demonstraram resistência e aceitaram a tarefa, a qual foi apresentada e trouxe um resultado bastante positivo, tendo em vista que foram apresentadas diferentes ferramentas, o que aguçou a curiosidade e o interesse dos professores por testar algumas das ferramentas durante o ano letivo. A Figura 1 representa, por meio de um mapa mental, as ferramentas que foram socializadas pelos professores. A apresentação foi iniciada com as primeiras quatro ferramentas (à esquerda), prosseguindo-se com as outras quatro (à direita).

Figura 1: Ferramentas digitais socializadas pelos professores.

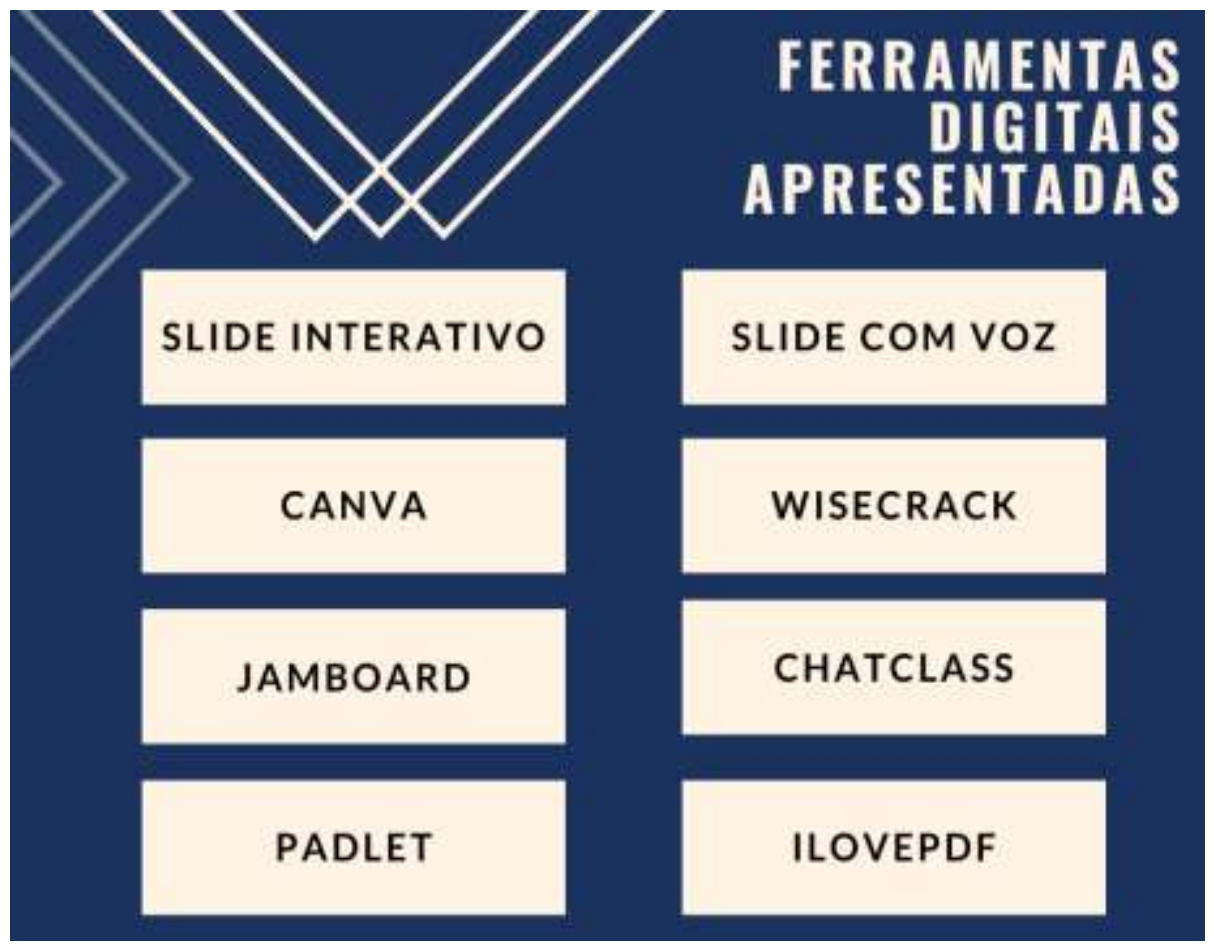

Fonte: Autores (2021).

Como podemos observar, a variedade de ferramentas apresentadas foi bastante interessante porque grande parte delas não era utilizada pela maioria dos professores. Cada uma delas era usada por um professor. Outro detalhe que chama a atenção é não ter aparecido na figura nenhuma menção a Whatsapp e Google Meet, ferramentas já utilizadas constantemente pelos professores, ou seja, ficou nítido nessa experiência que há diversas possibilidades disponíveis, cabendo ao professor ser curioso e inovador. Na sequência, trazemos um resumo de como se deu a experiência.

\section{Resultados e Discussão}

Seguindo a lógica da proposta lançada aos professores, a P1 apresentou um Slide Interativo bastante interessante. Uma produção chamativa, cheia de cores, imagens diferentes, links clicáveis e uma proposta de aula dinâmica que chamou a 
atenção de seus pares. Ela explicou o passo a passo de como fazer esse slide no Google Apresentações e trouxe como exemplo uma das suas produções utilizadas em 2020 durante suas aulas remotas.

Figura 2: Slide interativo.

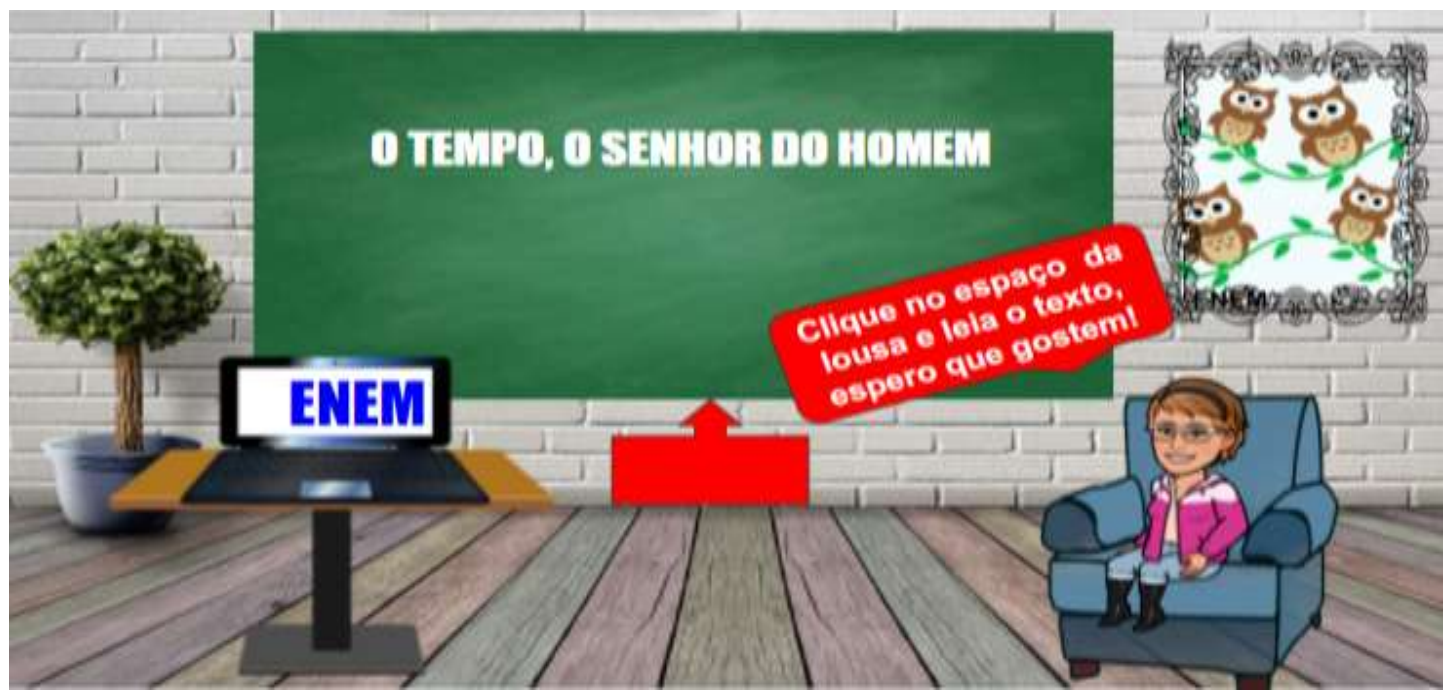

Fonte: Autores (2021).

A produção da professora é totalmente adequada para o contexto no qual estamos imersos porque trabalha com aquilo que os alunos mais gostam - interatividade. A partir desse cenário clicável, a professora consegue ministrar uma aula inteira explorando a multimodalidade (texto, vídeo, imagem, som, link, etc.). Há links em locais estratégicos deste cenário que, ao serem clicados, vão levando a diferentes recursos/materiais escolhidos pela docente para dar o contorno da aula. Esse cenário pode ser compartilhado com os alunos, para que, em momento oportuno, eles possam explorar todos os links disponíveis e chegar ao material organizado pela professora.

Segundo a professora sinalizou, enquanto fazia sua apresentação, uma das coisas que mais the chamaram a atenção foi a atenção dos alunos que, movidos pela curiosidade, ficavam querendo saber o que havia em cada link. Outro ponto de destaque foi a figura da professora sentada no sofá, com características da P1 (óculos, tiara e cabelo curto), que não passou despercebido pelos alunos.

A multimodalidade é uma marca bastante presente nos textos atuais, devido à disseminação cada vez mais acelerada das tecnologias digitais da informação e comunicação. Para Kress e Van Leeuwen (2001), a tessitura de um texto multimodal ocorre por meio da ligação de elementos verbais e não verbais e elementos semióticos extralinguísticos que juntos dão sentido ao texto. Assim, ao escolher trabalhar com o slide interativo, a docente oportuniza aos estudantes o contato com um tipo de texto diferente, que possibilita a eles criar sentido a partir de toda a arquitetura textual planejada.

O P2 apresentou a ferramenta $\mathrm{Canva}^{8}$, um recurso de grande valia para os professores, uma vez que possibilita a construção de mapas mentais, infográficos, posts, organogramas, gráficos, etc., de forma rápida e fácil, a partir de modelos préprontos oferecidos gratuitamente no site do aplicativo, cabendo aos interessados apenas editarem qualquer formato de acordo com seus gostos e necessidades.

Segundo Ferreira e Silva (2020, p. 03), o Canva:

\footnotetext{
${ }^{8}$ Disponível em https://www.canva.com/. Acesso em 31 de março de 2021.
} 
[...] é uma ferramenta online e disponível para Download em dispositivos IOS ou Android, com o intuito de desenvolver design autoral ou compartilhado, permitindo ao usuário capturar, construir e partilhar suas ideias e criações visualmente, ilustrar a partir da leitura de textos e da estrutura de diversas interfaces, sendo uma delas o uso de mapa mental.

Ou seja, trata-se de uma ferramenta de grande utilidade para profissionais de diferentes áreas, a exemplo da educação, ao possibilitar a criação, edição e compartilhamento de diferentes criações que ajudam na organização de aulas mais atrativas e dinâmicas sem nenhum custo já que, apesar de existir a versão paga, o Canva oferece centenas de possibilidades de designs gratuitos.

O professor mostrou o passo a passo de como utilizar a ferramenta e, na sequência, apresentou o mapa mental apresentado na Figura 3.

Figura 3: Mapa mental sobre competências digitais docentes.

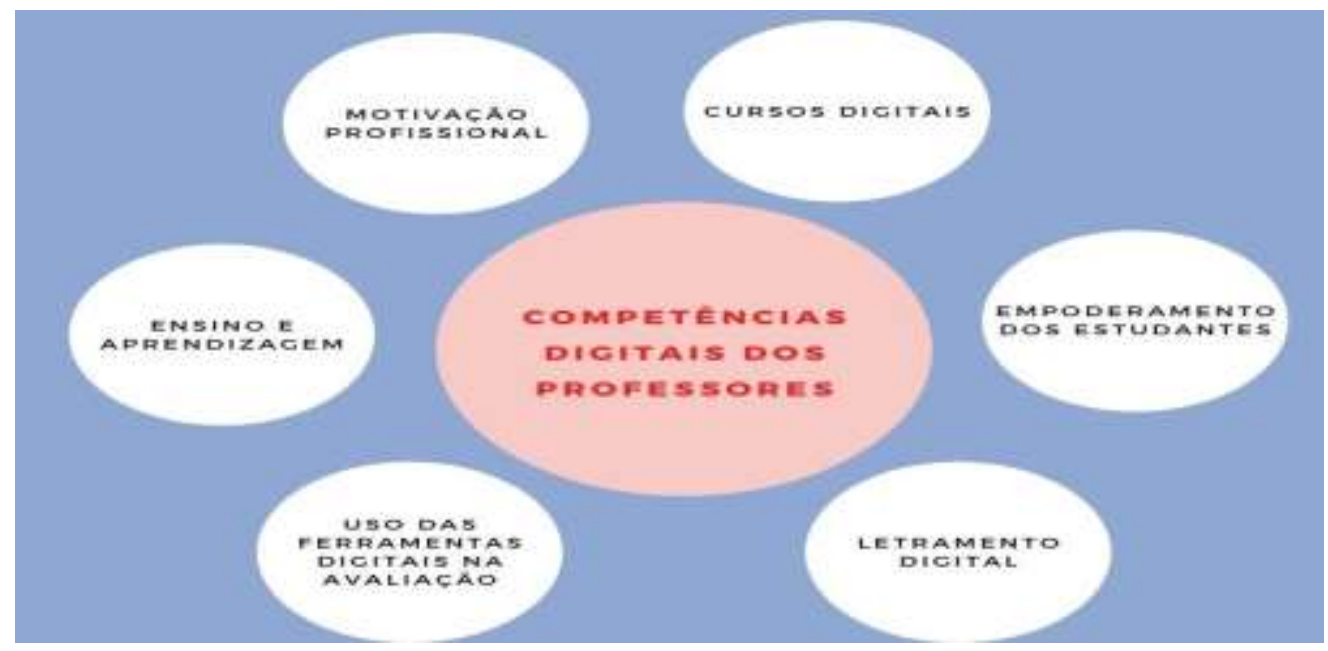

Fonte: Baseado em um estudo desenvolvido na Comissão Europeia ${ }^{9}$.

O mapa mental da Figura 3, mostra as competências digitais dos professores para o século XXI, algo totalmente relacionado às discussões empreendidas neste trabalho. Esse modelo já se encontra pronto no Canva, com outros tópicos, porém, pelo seu formato editável, o professor pode substituir todos os tópicos por outros do seu interesse. Além disso, ele pode retirar algumas partes do mapa, caso não necessite explorar muitos tópicos e pode aumentar o número de tópicos duplicando alguma das partes do desenho. O Canva dá a liberdade para o usuário modificar tudo: cores, formas, fontes, etc. Ele facilita muito a autonomia do usuário em criar seus próprios designs a partir dos modelos pré-prontos, o que vai ao encontro das ideias defendidas por Freire (1996) quando sinaliza a importância da autonomia discente no processo de construção da própria aprendizagem.

Para além de todo o leque de possibilidades de modelos oferecidos gratuitamente pelo Canva, uma das características que mais se destacam é a qualidade dos designs, totalmente profissionais. Esse tipo de produção, até pouco tempo, era realizado por profissionais com formação e habilidade na área do Design, algo oferecido gratuitamente hoje ao grande público num momento em que a socialização de diferentes ferramentas digitais cresce significativamente.

\footnotetext{
${ }^{9}$ Disponível em: https://area.dge.mec.pt/download/DigCompEdu_2018.pdf. Acesso em 31 de março de 2021.
} 
Conforme o professor, o mapa mental apresenta um grande potencial principalmente porque consegue prender a atenção dos alunos durante um bom tempo e ele pode explicar um conteúdo longo com a sensação de estar dando muito conteúdo, algo que os alunos reclamam quando o professor faz uma longa apresentação de slides.

O P3 socializou a ferramenta Jamboard ${ }^{10}$, mostrando o passo a passo dessa ferramenta. Trata-se de um quadro branco digital inteligente que faz parte do pacote de aplicativos do G Suite For Education. Essa ferramenta é bastante útil porque permite ao professor utilizar essa lousa durante a aula online para mostrar exemplos, realizar operações matemáticas e fazer qualquer tipo de anotação/observação que facilite a compreensão por parte dos alunos. Com o próprio mouse, o professor seleciona uma caneta ou pincel com o qual escreverá no jamboard, tendo também o recurso da borracha para apagar. Ele ainda tem a opção de utilizar uma caneta especial para escrever na própria tela do notebook, caso ele seja touch screen. A Figura 4 mostra um print de um dos momentos da aula em que o professor Laranja utilizou o jamboard.

Figura 4: Utilização do Jamboard em Aula Online.

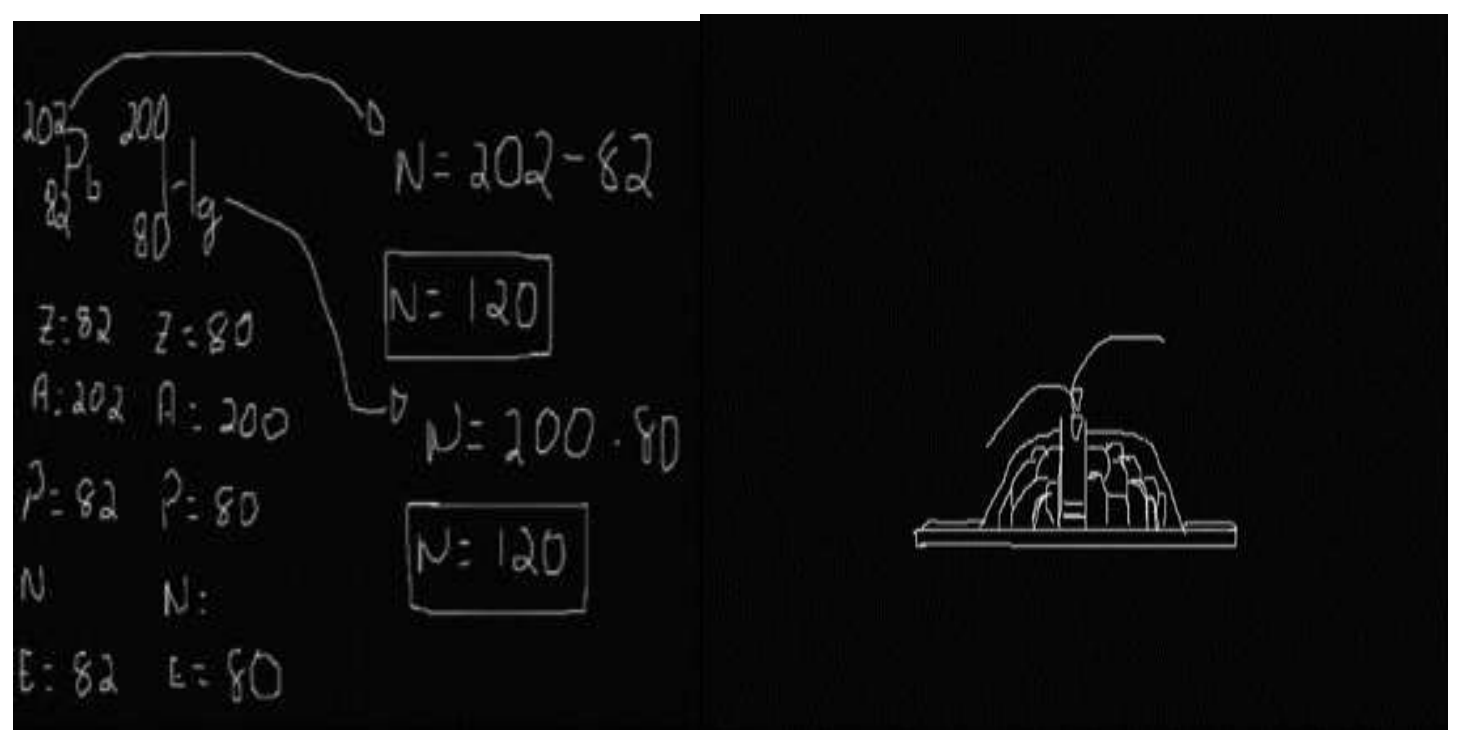

Fonte: Autores (2021).

A Figura 4 retrata dois momentos da aula do professor: o primeiro, a realização de um cálculo, o segundo, o desenho de um vulcão. Segundo o próprio docente, essa ferramenta é de grande valia para esse momento de ensino remoto porque permite aos professores de exatas continuarem com sua didática de explicar o passo a passo da resolução de um cálculo ou problema matemático ou de física utilizando o quadro (nesse caso, o virtual), algo que se aproxima muito da aula tradicional. A utilização dessa ferramenta é importante porque nesse tipo de disciplina, não faz muito efeito o professor apenas falar sozinho. É preciso o passo a passo da resolução do problema, o ensinar a fazer fazendo e, essa possibilidade digital, apesar da distância geográfica, aproxima alunos e professores, algo sinalizado pelo professor como muito positivo, apesar da distância geográfica.

Assim, "precisamos nos aproximar e compreender que as novas tecnologias digitais oferecem um desafio viável, visto que a aprendizagem pode acontecer em qualquer hora e lugar e de diferentes modos. Assim, a tecnologia digital pode ser uma grande aliada no processo de ensino-aprendizagem escolar" (Mendes; Champaoski, 2017, p. 428).

${ }^{10}$ Disponível em: https://edu.google.com/intl/pt-BR/products/jamboard/. Acesso em 31 de março de 2021. 
A P4 socializou sua experiência e habilidade com o Padlet $^{11}$, uma ferramenta que oportuniza ao professor realizar diversos tipos de atividades, tanto síncronas, quanto assíncronas, muito atrativas para o ensino remoto. Trata-se de um mural virtual utilizado para a exposição de diferentes atividades. Por ser multimídia, o Padlet é bastante interativo e multimodal, sendo possível a inserção de diferentes conteúdos (texto, vídeo, imagem, link, etc.). Na Figura 5 podemos observar um Padlet produzido pela professora e a participação dos alunos numa atividade interativa.

Figura 5: Fórum de Discussão no Padlet.

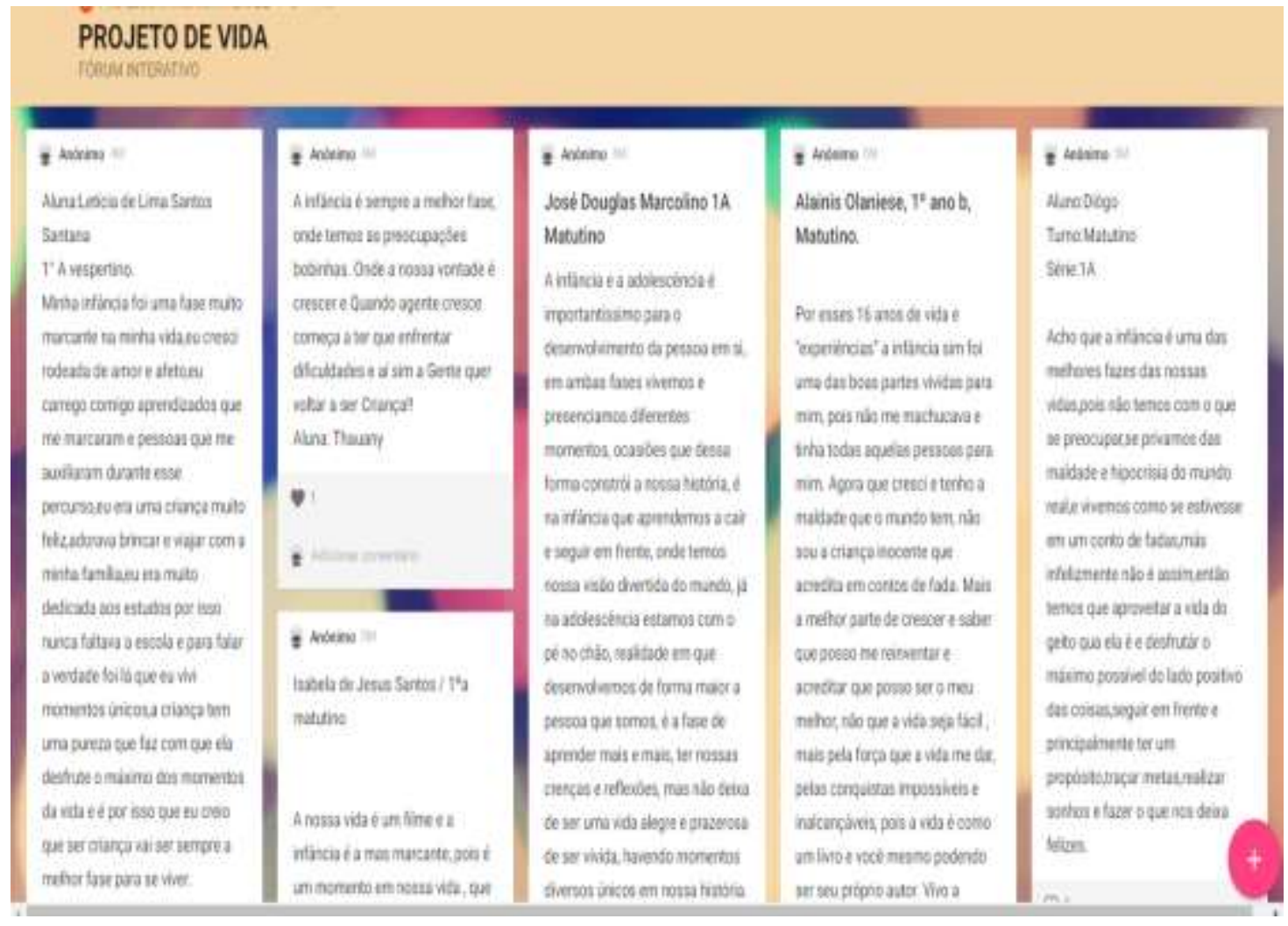

Fonte: Autores (2021).

Como se nota na Figura 5, a professora criou esse mural virtual para estabelecer uma discussão com sua turma da disciplina Projeto de Vida, tendo como temática memórias da infância e sua importância para a construção do eu. Essa proposta de atividade, de acordo com a professora, é bastante interessante porque possibilita aos alunos a oportunidade de falar um pouco sobre si mesmos sem ter que utilizar a oralidade, já que muitos, pela timidez, geralmente não têm coragem de falar, mas, na escrita, sentem-se mais confortáveis. Além disso, essa atividade contribui para a melhoria da produção textual dos estudantes, sem contar na possibilidade de leitura dos textos dos colegas e confronto com os próprios, para a percepção de semelhanças e diferenças entre as infâncias. Conforme a explicação da professora, essa atividade tanto pode ser feita de forma síncrona (durante a aula), como assíncrona (fora da aula), ficando o Padlet disponível para os alunos fazerem suas postagens quando quiserem. Nesse contexto,

É preciso quebrar alguns paradigmas e reconhecer a necessidade de trazer a tecnologia digital para dentro da sala de aula para promover uma educação de qualidade que atenda a demanda do atual contexto que vivemos. A escola precisa assumir postura didática de comprometimento oferecendo ao aluno diversas possibilidades de aprendizagem (Hess; Assis; Viana, 2019, p. 120).

${ }^{11}$ Disponível em: https://pt-br.padlet.com/. Acesso em 01 de abril de 2021. 
Dessa forma, ao trazer para a sala de aula virtual o Padlet e construir a partir dele diferentes possibilidades de aprendizagem, a professora demonstra que compreende a necessidade desse momento pandêmico, que requer dos professores diferentes habilidades com as tecnologias digitais para ensinar e aprender.

A P5 nos apresentou o Slide com voz, algo simples de fazer, a partir de algumas instruções rápidas dentro do próprio powerpoint, e que possibilita ao aluno a oportunidade de ouvir a voz da professora dentro do próprio slide, algo que se aproxima muito de uma aula. Ela apresentou aos pares todos os procedimentos para a criação do slide e escolheu uma de suas produções (sistema digestório) para socializar com os colegas.

Figura 6: Aula sobre o Sistema Digestório.

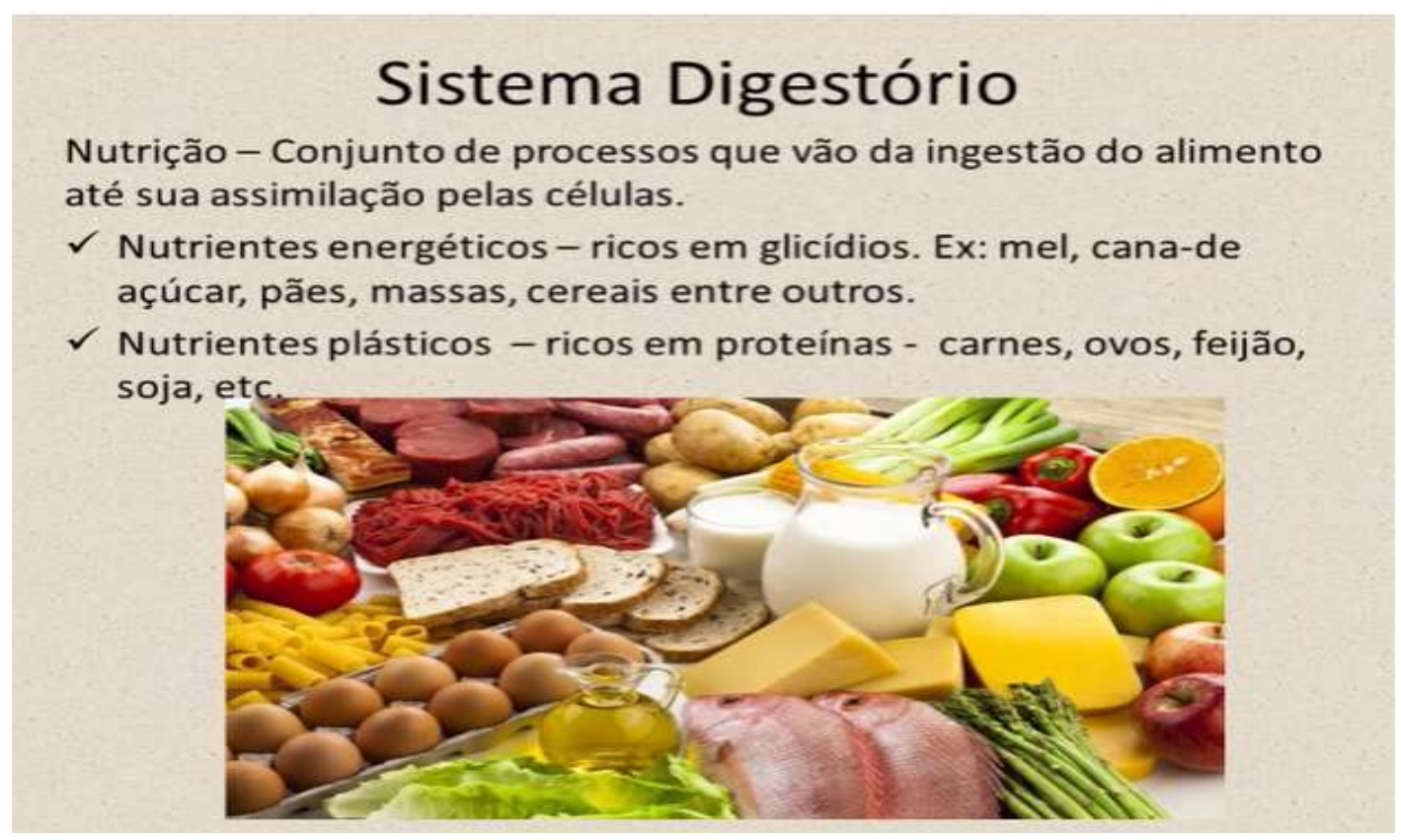

Fonte: Autores (2021).

Nesse slide, à medida que ele vai sendo apresentado, a professora vai fazendo a explicação do conteúdo, utilizando, durante alguns momentos, o recurso do laser para apontar para algum local específico. Ela também tem a possibilidade de grifar, circular e fazer outros tipos de marcações que colaboram para a compreensão do conteúdo. Apesar de simples e tradicional, já que é a simulação de uma aula comum, esse recurso foi muito útil para a professora porque, segundo ela, a livrou de postar vídeos do Youtube para os alunos, algo que a distanciaria dos mesmos e que já era apontado pelos alunos como algo cansativo, tendo em vista que muitos vídeos postados por outros professores, diretamente do Youtube, eram muito longos, algo que levava à perda de interesse dos alunos.

Vale frisar que, a professora optou por postar esses slides com voz no Google Classroom de suas turmas e que, em alguns momentos, os alunos reclamavam que não conseguiam abrir. Assim, uma solução para esse problema seria ela salvar esses slides com voz no formato WMF (Windows media file) e disponibilizá-los no Youtube, assim os alunos assistiriam sem dificuldade.

No Youtube, por mais que os vídeos tratem do mesmo conteúdo, a linguagem dos professores geralmente se distancia da dos alunos do contexto em questão. Nesse caso, ouvir a voz da professora em tempos de ensino remoto aproximava os alunos e trazia um certo conforto para eles, algo sinalizado pela professora, uma vez que os alunos gostaram 
bastante de receber esse tipo de aula no Whatsapp e no Google Classroom. Além disso, essa preocupação da professora em se manter próxima dos alunos é fundamental para o estreitamento da relação educador/educando.

Nesse viés, "a relação professor-aluno abrange todas as dimensões do processo ensino aprendizagem que se desenvolve em sala de aula, e muitas vezes é importante transpor os papéis formais da atividade docente, dando estrutura ao aprendizado, orientando e ajudando os alunos a estudar e aprender" (Brait et al., 2010, p. 14). Ou seja, ao observar quais as melhores maneiras de os alunos estudarem nestes tempos de pandemia, a docente demonstra uma preocupação com eles e com o resultado do processo de ensino-aprendizagem. Ela poderia simplesmente utilizar vídeos prontos na internet sobre o conteúdo Sistema Digestório e compartilhar com os alunos, mas essa escolha os distanciaria. Por isso, por mais que ela gaste tempo gravando e regravando seus próprios vídeos, ela sabe que os resultados serão mais proveitosos.

O P6 socializou um canal do Youtube denominado Wisecrack ${ }^{12}$, no qual é possível aprofundar os conhecimentos de Filosofia, Literatura, Música, Teatro, Quadrinhos e Games a partir da comédia, uma possibilidade de quebrar um pouco o tradicionalismo das aulas, principalmente de Filosofia e Literatura, a partir da arquitetura dos jogos, de forma divertida e, ao mesmo tempo, construindo conhecimentos. Ele apresentou o canal, fez uma descrição detalhada do mesmo e do seu potencial para o ensino e socializou do canal o vídeo apresentado na Figura 7.

Figura 7: Explorando a Filosofia através de Jogos.

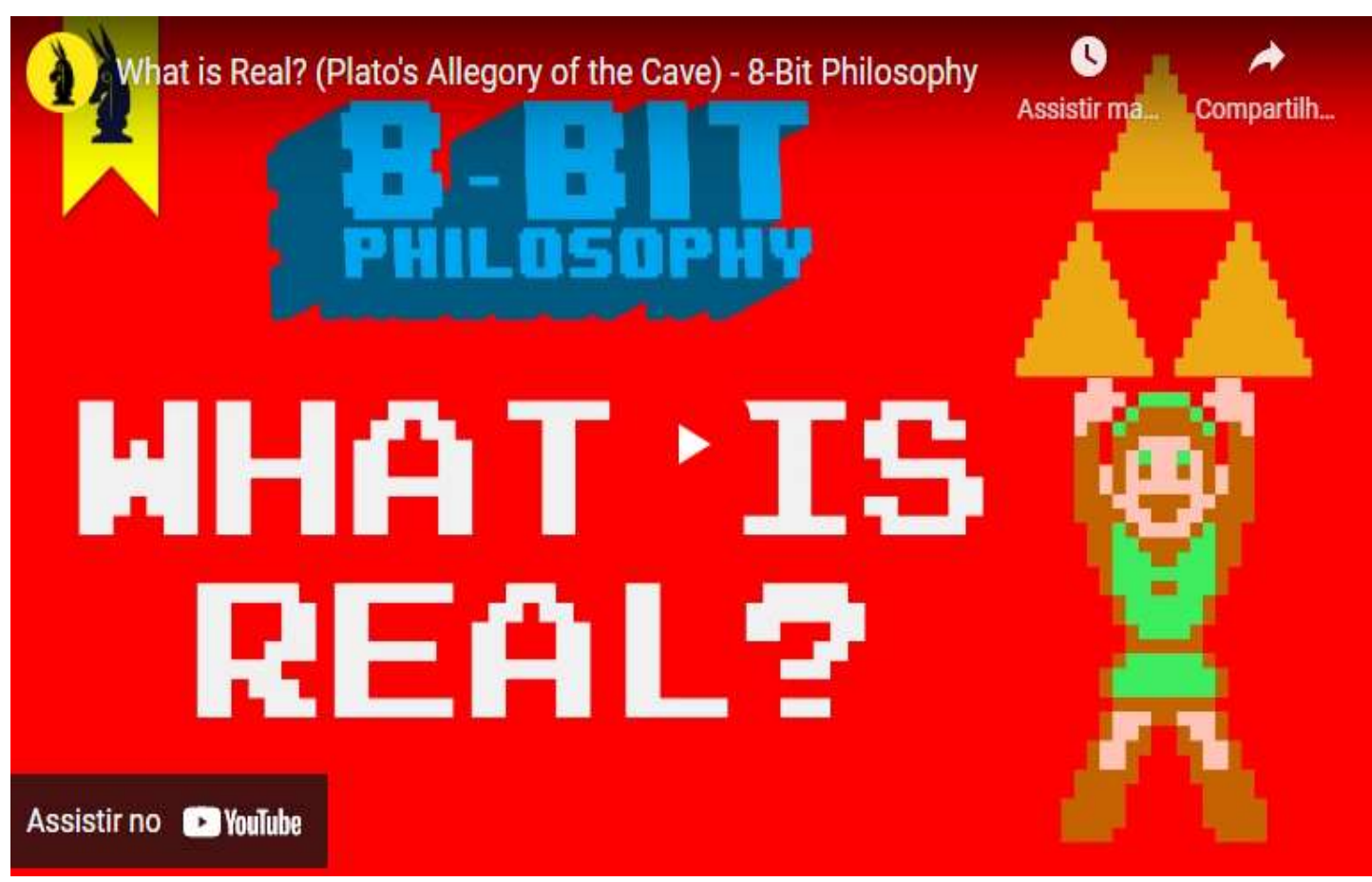

Fonte: https://www.youtube.com/watch?reload=9\&v=1VDaSgyi3xE.

O jogo representado na Figura 7, por exemplo, pode ser utilizado pelo professor de Filosofia para trabalhar um assunto muito complexo para os alunos no início dos estudos da área - o famoso Mito da Caverna, de Platão. Como os alunos do ensino médio geralmente têm um fascínio pelos jogos, poder estudar/discutir este assunto a partir deste jogo é algo que chama a atenção dos estudantes. O jogo tem o formato dos famosos games do Mario Bros, algo que remete à infância de muitos alunos que jogavam esses games. Assim, fazer uso de jogos é um caminho fecundo para novas práticas de ensino e

${ }^{12}$ Disponível em: https://www.youtube.com/channel/UC6-ymYjG0SU0jUWnWh9ZzEQ. Acesso em 01 de abril de 2021. 
Research, Society and Development, v. 10, n. 4, e33710414156, 2021

(CC BY 4.0) | ISSN 2525-3409 | DOI: http://dx.doi.org/10.33448/rsd-v10i4.14156

aprendizagem, principalmente no contexto do ensino remoto. A esse respeito, de acordo com Alves e Bianchin (2020, p. 285), "os jogos não são apenas uma forma de divertimento: são meios que contribuem e enriquecem o desenvolvimento intelectual", por isso, o jogo em questão apresenta grande potencial para a aprendizagem discente. Assim, a ideia do professor em usar um canal do Youtube para discutir Filosofia a partir da arquitetura dos games é uma ótima opção para o momento atual e uma forma de aproximação dos alunos.

O P7 apresentou uma ferramenta chamada Chatclass $^{13}$, que trabalha com inteligência artificial. Essa ferramenta é diferente porque possibilita aos estudantes de todo o Brasil a oportunidade de testarem seus conhecimentos de diferentes disciplinas através do Whatsapp. O Chatclass permite que os alunos revisem conteúdos a partir da resolução de inúmeras questões disponíveis no aplicativo. Além disso, o aluno é auxiliado por um robô, que vai orientando-o em todo o percurso da atividade, inclusive avisando quando acertou a questão, quando errou, sua pontuação, ranking dos estudantes com maior número de acertos, etc. Na Figura 8, podemos ver alguns prints de uma atividade realizada no Chatclass.

Figura 8: Utilização do Chatclass.

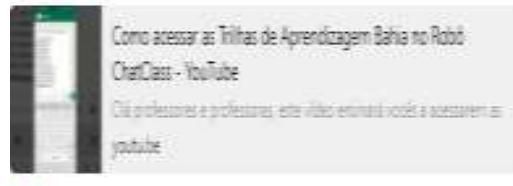

G- Conandss

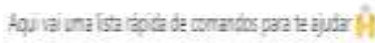

hicis- votw ac net ince

r-incer a priminatidats

Trocar- yescar cortaido de outses arces

Auba-is c nesu ajub

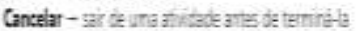

Explorer - ver a isto de thinas

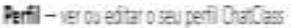

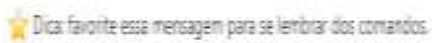

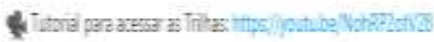

Dgesk zacu cortinas

is ination

Explamaturnasary

A) Orallem Teacten
A) ChatClass Teachers

B) prof_sociologia_em1

C) prot_sociologia,em2

D) prof_sociologia_em?

Digite a letra da opça desejada, ou cancelar para sait.

A Encominhods

Prontol Podemos começar, Noilson!

7 Ir para os exercicios

1 Meu perfil

Escolha a opçao digitando a palavra destacada.

-

\section{Gsgsosg}

A Bncomintiofo

(i.) Hmm... Eu nào entend.

A Encominhose

Prontol Podemos começar, Noilson!

7 Ir para os exercicios

- Meu perfil

Escolha a opçao digitando a palavia destacada.
Começando a prồma atuidade da unidade 14 Sociologia - Trilha 1.

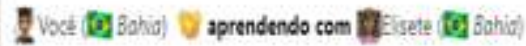

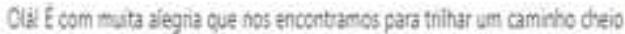
de descotertas. Voce teria a oporturidade de reiletir um pouto mas sobre 0 conhecimento cientifico e o saber popdar relacionands.cs as iake news voci. tera oportunidade de expressar o que aprendeu e comoant iha seus conhecimentos sobre 0 assunto.

Ah filo se prescupe caninharenos juntos nessa super missto de trilhar pelc caminhe do conhecinents. Aproveste a prnada esiganos caminhando!

4 iranituas

1/4:0 tema Fake Neres genhou anda mair destaque com o surginento do Coronavinas. A medida que os casos eram coctimados o voume de informąbes faisas tambeimt juttentou.

Como vose faz pan identficar notioas faisas ciante da grande quantidade de Informaçóes que acessamch diaramente na rțternat?

A) Se for uma informaçio que envolia uma emprest ou doglo do governo. acerso o site of od da intotuicho parz ver se tem alguma informa,blo scole a postagen recebida.

B) Confio na mensagem se éa tiver imagens ou a logomara das empressc;

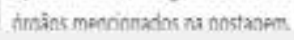

Fonte: Autores (2021).

A Figura 8 apresenta alguns prints que o professor utilizou para explicar o passo a passo de como utilizar o Chatclass. É possível ver os comandos dados a alunos e professores pelo robô no Whatsapp, o percurso que eles devem seguir para chegar às atividades/disciplinas desejadas para testar/ampliar seus conhecimentos. Essa ferramenta pode ser utilizada a qualquer momento pelos alunos, sem a necessidade de acompanhamento do professor, pois no próprio Whatsapp, a partir dos recursos da inteligência artificial, o aluno tem o feedback, inclusive com orientação para estudos de conteúdos relativos às questões que eles erraram.

\footnotetext{
${ }_{13}$ Disponível em: http://jornadapedagogica.educacao.ba.gov.br/wp-content/uploads/2021/03/ChatClass-Bahia_Links.pdf. Acesso em 31 de março de 2021.
} 
Vale ressaltar que a ChatClass é uma Edtech fundada em Nova York, que visa democratizar o ensino de inglês utilizando inteligência artificial. A plataforma utiliza ferramentas presentes no dia a dia dos brasileiros, como o Whatsapp, e já impactou mais de 400 mil alunos de escolas públicas e particulares ${ }^{14}$. O estado da Bahia já havia trabalhado com essa ferramenta em 2019 e 2020, durante as olimpíadas de inglês. Este ano, devido às novas demandas que o cenário pandêmico impôs, a secretaria disponibilizou aos professores da rede estadual Chatclass de quase todas as disciplinas, para que os alunos tenham mais possibilidades de aprender se divertindo, pois, como há um ranking no Brasil, muitos alunos se sentem estimulados a estarem entre os melhores do país em determinadas disciplinas.

De acordo com Martins e Maschio (2014, p. 17), "um dos desafios da formação dos professores para o uso das novas tecnologias digitais é desenvolver nos professores a capacidade de perceber a potencialidade dos recursos educacionais digitais". Nesse caso, fica nítido que o professor, ao escolher o Chatclass como ferramenta pedagógica, já percebeu sua potencialidade para o ensino e consegue tirar proveito dela para aulas mais condizentes com esse perfil de aluno que nasceu na era digital. Além disso, "[...] a familiaridade com as tecnologias facilita ao professor utilizar determinado recurso. O domínio da ferramenta [...] faz com que o professor fique à vontade para fazer uma avaliação crítica do potencial desses recursos para poder definir, criar ou adotar práticas pedagógicas para trabalhar com seus alunos" (Modelski; Azeredo; Giraffa, 2018, p. 121).

O P8 socializou a ferramenta Ilovepdf ${ }^{15}$, bastante útil atualmente para diversos fins, principalmente acadêmicos e profissionais. Por meio dela, é possível juntar vários documentos pdf (portable document format) em um só e formar uma apostila, podendo inclusive numerar todas as páginas; é possível também a separação de pdf (quando a pessoa só precisa de alguns capítulos ou folhas específicas); pode-se comprimir arquivos, tornando-os mais leves para serem enviados online, entre outras possibilidades. A Figura 9 mostra as diferentes funcionalidades dessa ferramenta, algumas delas demonstradas no próprio site pelo professor utilizando arquivos pessoais.

\footnotetext{
${ }^{14}$ Disponível em: https://www.chatclass.com.br/sobre\#: :text=A\%20ChatClass\%20\%C3\%A9\%20uma\%20Edtech,de\%20escolas\%20p\%C3\%BAblicas\%20e\% 20particulares. Acesso em 01 de abril de 2021.

${ }^{15}$ Disponível em: https://www.ilovepdf.com/pt. Acesso em 01 de abril de 2021.
} 
Research, Society and Development, v. 10, n. 4, e33710414156, 2021

(CC BY 4.0) | ISSN 2525-3409 | DOI: http://dx.doi.org/10.33448/rsd-v10i4.14156

Figura 9: Funcionalidades do Ilovepdf.

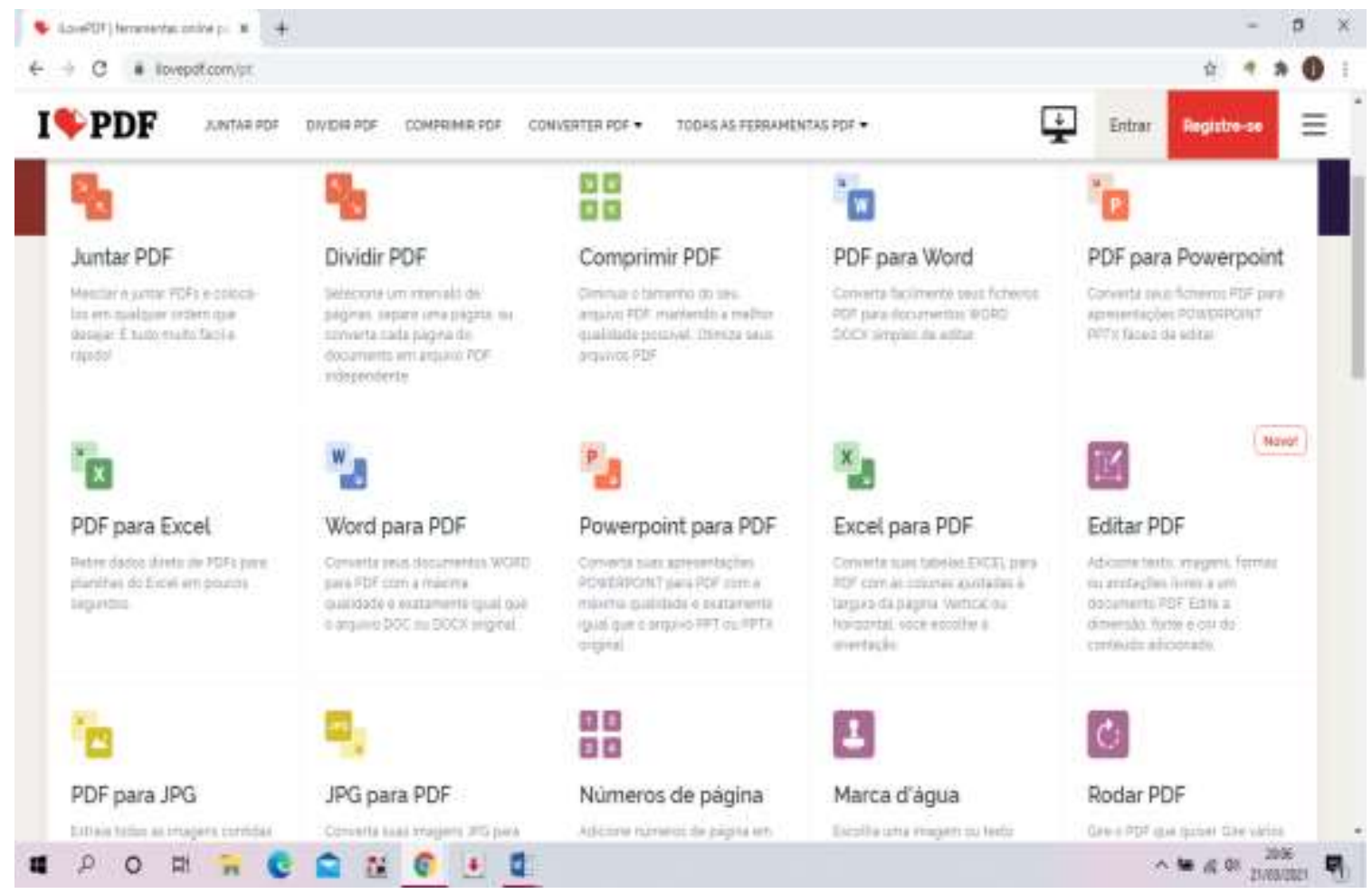

Fonte: Ilovepdf.com.

Como fica explícito na Figura 9, o leque de possibilidades de conversão e de utilização da ferramenta Ilovepdf é muito grande, sem contar que existem mais sete opções que não foram mostradas na imagem. Na Figura 10, podemos ver a demonstração da junção de dois documentos em pdf feitas pelo professor.

Figura 10: Utilização do Ilovepdf.

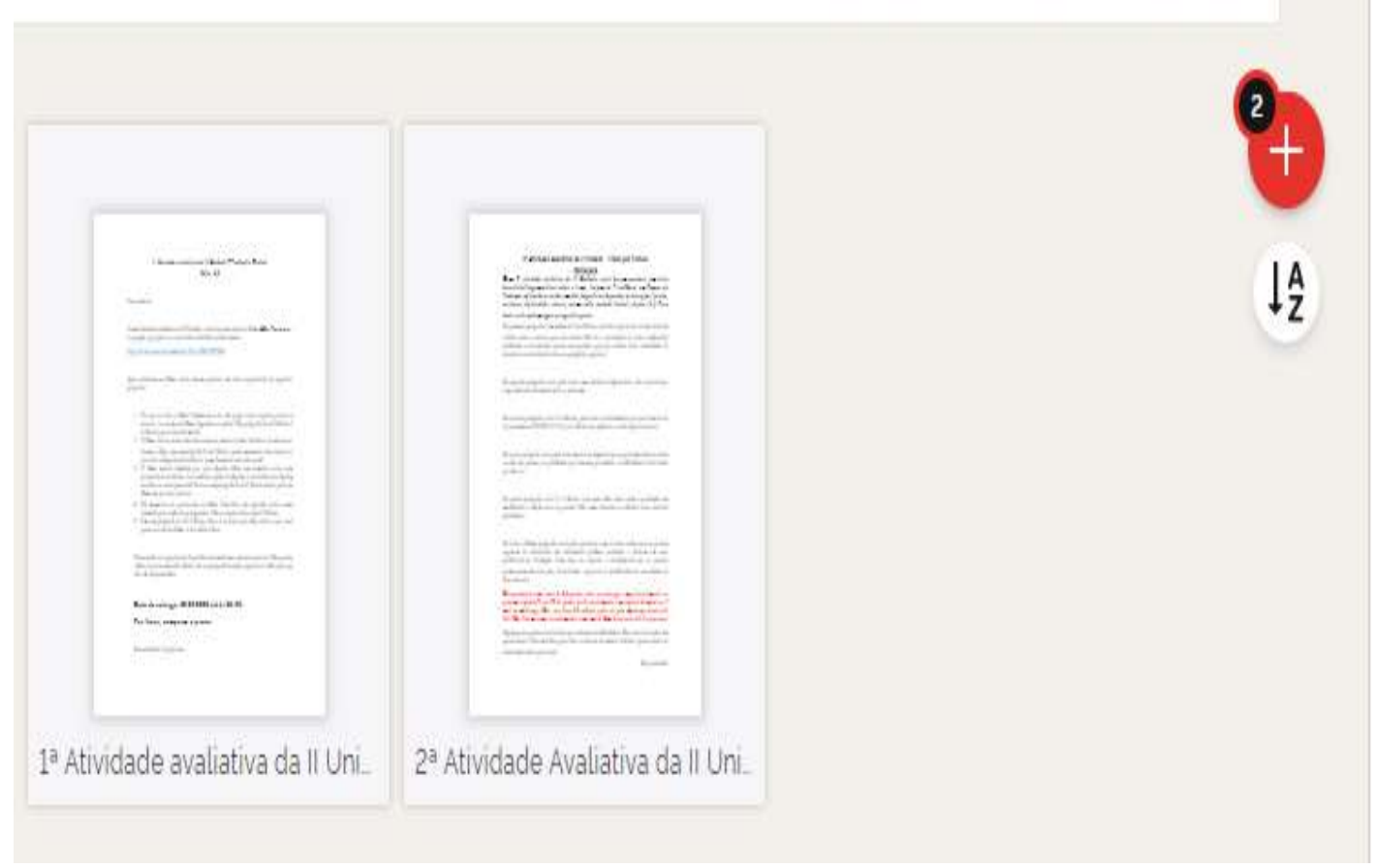

Fonte: Ilovepdf.com. 
A Figura 10 mostra o processo inicial de junção de documentos a partir da ferramenta Ilovepdf. É possível ver duas atividades sendo unidas em um único documento. O botão vermelho, com o sinal de adição, mostra a quantidade de documentos que foram selecionados e que novos documentos podem ser adicionados à medida que o usuário clica no botão vermelho. Selecionados os documentos desejados, clica-se em juntar, o que é feito em questão de segundos e o usuário recebe um documento único, o qual ele baixa no computador. É uma ferramenta gratuita e muito fácil de usar, além de auxiliar bastante as pessoas que necessitam desse tipo de serviço.

Conforme o professor, um dos pontos que mais chamou a atenção dos alunos na demonstração da ferramenta foi a possibilidade de comprimir documentos, principalmente porque eles leem muito no celular, que muitas vezes não consegue carregar nem abrir determinado documento em pdf por conta de o arquivo ser grande. Com a possibilidade de comprimir, os arquivos ficam bem leves e podem ser socializados sem dificuldade.

Nesse contexto marcado pela presença constante das tecnologias digitais, é preciso lembrar que "[...] estamos em uma época de grandes transformações, e todos nós temos três opções: temê-las, ignorá-las ou aceitá-las" (Jenkins, 2009, p. 09). Portanto, é fundamental aceitá-las, afinal, elas estão em toda a parte e, se bem usadas, podem nos trazer diversos benefícios.

Portanto, percebe-se, a partir desse relato de experiência que, em quaisquer adversidades, com união, os professores conseguem superar os obstáculos e prosseguir seu trabalho com qualidade. Nesse momento pandêmico não seria diferente. Os problemas surgiram, mas os professores não se abateram e pensaram juntos em novas possibilidades. Ou seja, nesse contexto de cultura digital, a conscientização do trabalho conjunto com outros professores, as trocas conceituais e metodológicas em prol de uma aprendizagem significativa para alunos e professores é fundamental (Lima; Loureiro, 2015). Assim, a Jornada Pedagógica Paulo Freire 2020/2021 foi um campo fértil de construção e socialização de conhecimento.

\section{Considerações Finais}

Este trabalho se incumbiu de apresentar uma experiência exitosa acerca do uso de tecnologias digitais por professores do ensino médio em um colégio da rede estadual da Bahia, experiência esta que resultou na troca de conhecimentos entre os docentes sobre o uso de tecnologias digitais nos processos de ensino e de aprendizagem.

Diante de um contexto de dificuldades, por conta da pandemia de Covid-19, a socialização de diferentes conhecimentos tecnológicos entre os docentes foi fundamental para a mudança de postura no colégio em questão, pois os professores passaram a entender que, por mais que haja certas dificuldades para utilizar determinadas ferramentas, não há motivo para resistência, e que é preciso estar aberto para aprender a usá-las em prol de um ensino adequado às necessidades do momento.

Ficou nítido também, a partir deste trabalho, que o uso das tecnologias digitais em si não são o diferencial para aulas mais inovadoras, pois elas são apenas o meio, não o fim. Ou seja, por mais que elas sejam importantes e necessárias, mais importante ainda é a capacidade do professor de perceber suas potencialidades e usá-las em prol do ensino. Não adianta usar tecnologias digitais para ensinar sem saber contextualizá-las com o objetivo da aula.

Assim, ao retomarmos nossa questão de pesquisa (como os professores têm encarado a necessidade de levar adiante o ensino remoto a partir do uso de tecnologias digitais?), notamos que ela foi respondida ao longo deste trabalho, uma vez que os professores encararam a necessidade de levar o ensino adiante por meio do uso de tecnologias digitais com muito entusiasmo e mostraram que a vontade de aprender e de oferecer um ensino de qualidade é algo que está acima de qualquer dificuldade. 
Research, Society and Development, v. 10, n. 4, e33710414156, 2021

(CC BY 4.0) | ISSN 2525-3409 | DOI: http://dx.doi.org/10.33448/rsd-v10i4.14156

Em suma, este trabalho nos permitiu enxergar que, aprender a aprender é algo que o professor precisa exercitar com frequência, pois, por mais que ele tenha muitos anos de experiência, ele continuará aprendendo para dar conta de novos cenários e novos públicos.

\section{Agradecimentos}

A todo o corpo diretivo, pedagógico e docente do Colégio Estadual Professora Luzia Carvalho Silva pelos dados fornecidos para esta pesquisa.

\section{Referências}

Almeida, N. A. et al. (2015). Tecnologia na escola: abordagem pedagógica e abordagem técnica. Cengage Learning.

Alves, L.; \& Bianchin, M. A. (2010). O jogo como recurso de aprendizagem. Rev. Psicopedagogia, 27(83), $282-287$.

Braga, D. B. (2013). Ambientes Digitais: reflexões teóricas e práticas. Cortez.

Brait, L. F. R. et al. (2010). A relação professor/aluno no processo de ensino e aprendizagem. Revista Eletrônica do Curso de Pedagogia, 8 (1), 1-15.

Carvalho, F. C. A.; \& Ivanoff, G. B. (2010). Tecnologias que educam: ensinar e aprender com tecnologias da informação e comunicação. Pearson Prentice Hall.

Daltro, M. R.; \& Faria, A. A. (2019). Relato de Experiência: uma narrativa científica na pós-modernidade. Estudos e Pesquisas em Psicologia, 19, (1), 223237.

Ferreira, L. F. S.; \& Silva, V. M. C. B. (2020). Research, Society and Development, 9, (8), 1-16.

Freire, P. (1996). Pedagogia da autonomia: saberes necessários à prática educativa. Paz e Terra.

Hess, L. W. B.; Assis, R. M. N.; Viana, H. B. (2019). Inserção das Tecnologias Digitais na Prática Docente. Laplage em Revista, 5 , (2), 119-127.

Jenkins, H. (2009). Cultura da convergência. Aleph.

Kress, G.; \& Van L., T. (2001). Multimodal Discourse: The modes and media of contemporary communication. Oxford Press.

Lima, L; Loureiro, R. C. (2015). Integração entre tecnologias digitais e docência: a compreensão de grupos interdisciplinares. EDUCERE - XII Congresso Nacional de Educação. Disponível em: https://educere.bruc.com.br/arquivo/pdf2015/16235_7273.pdf.

Ludke, M.; \& André, M. (1986). Pesquisa em Educação: abordagens qualitativas. EPU.

Martins, O. B.; \& Maschio, E. C. F. (2014). As tecnologias digitais na escola e a formação docente: representações, apropriações e práticas. Revista Actualidades Investigativas em Educación, 14, (3), 1-21.

Mendes, A. A. P.; \& Champaoski, E. B. (2017). Percepção de Professores do Ensino Fundamental I acerca das Tecnologias Digitais no Cotidiano Escolar. Revista Intersaberes, 12, (26), 415-430.

Modelski, D.; A., \& Isabel; G., L. (2018). Formação Docente, Práticas Pedagógicas e Tecnologias Digitais: reflexões ainda necessárias. Revista Eletrônica Pesquiseduca, 10, (20), 116-133.

Oliveira, T. M. R. de; A., \& Carmem, L. C. (2020). O uso do aplicativo Whatsapp como recurso didático: uma experiência no ensino fundamental anos finais Tear: Revista de Educação, Ciência e Tecnologia, 9, (1), 1-12.

Ostrovski, C. S.; \& Raitz, T. R. (2016). Tecnologias e formação para o trabalho docente na sociedade contemporânea. Revista Educação e Cultura Contemporânea, 13, (31), 181-201.

Rampazzo, S. E.; \& Corrêa, F. Z. M. (2008). Desmistificando a Metodologia Científica: guia prático de produção de trabalhos acadêmicos. Habilis.

Vicente, M. P.; \& Almeida, J. G. (2017). Formação inicial e novas tecnologias: uma aproximação necessária na formação de professores. Revista Educação \& Tecnologia, 17, 1-10. 